\title{
The Treatment of International Issues in Taiwan's High School EFL Textbooks
}

\author{
Ya-Chen Su \\ Southern Taiwan University of Science and Technology, Taiwan
}

\begin{abstract}
The spread of English language throughout the world had led to its status as a global lingua franca. English language teaching (ELT) not only instructs in language, but also helps learners develop their awareness and understanding of international relationship around the world. The purpose of this study is to compare how international issues are presented in Taiwanese English as a Foreign Language (EFL) textbooks. One set of EFL commercial textbooks at the high school level published by Taiwanese publishing houses are chosen for analysis. The methodology focuses on content analysis. Two themes are examined: (1) international connection and interdependence and (2) globalization and its impacts on language and culture. Results found that the texts generally promote positive illustrations of technology development, global economy, and global media on human lives. On other hand, the sensitive and contradictive issues related to economic, linguistic, and cultural imperialism caused by globalization and technology are excluded.
\end{abstract}

Keywords: EFL textbooks, EFL teaching, globalization, international connection and interdependence, textbook analysis, Taiwan 